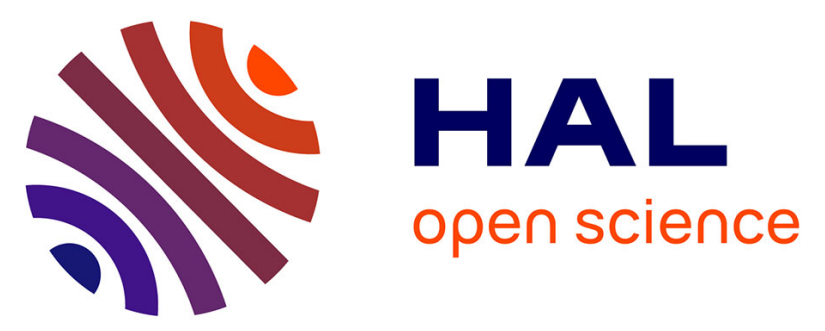

\title{
Suitability of the Pest-Plant System Tuta absoluta (Lepidoptera: Gelechiidae)-Tomato for Trichogramma (Hymenoptera: Trichogrammatidae) Parasitoids and Insights for Biological Control
}

Anais Chailleux, Antonio Biondi, Peng Han, Elisabeth Tabone, Nicolas

Desneux

\section{To cite this version:}

Anais Chailleux, Antonio Biondi, Peng Han, Elisabeth Tabone, Nicolas Desneux. Suitability of the Pest-Plant System Tuta absoluta (Lepidoptera: Gelechiidae)-Tomato for Trichogramma (Hymenoptera: Trichogrammatidae) Parasitoids and Insights for Biological Control. Journal of Economic Entomology, 2013, 6 (106), pp.2310-2321. 10.1603/EC13092 . hal-02648694

\section{HAL Id: hal-02648694 \\ https://hal.inrae.fr/hal-02648694}

Submitted on 29 May 2020

HAL is a multi-disciplinary open access archive for the deposit and dissemination of scientific research documents, whether they are published or not. The documents may come from teaching and research institutions in France or abroad, or from public or private research centers.
L'archive ouverte pluridisciplinaire HAL, est destinée au dépôt et à la diffusion de documents scientifiques de niveau recherche, publiés ou non, émanant des établissements d'enseignement et de recherche français ou étrangers, des laboratoires publics ou privés. 


\title{
Suitability of the Pest-Plant System Tuta absoluta (Lepidoptera: Gelechiidae)-Tomato for Trichogramma (Hymenoptera: Trichogrammatidae) Parasitoids and Insights for Biological Control
}

\author{
ANAÏS CHAILLEUX, ${ }^{1,2,3}$ ANTONIO BIONDI, ${ }^{1,4}$ PENG HAN, ${ }^{1}$ ELISABETH TABONE, ${ }^{5}$ \\ AND NICOLAS DESNEUX ${ }^{1}$
}

J. Econ. Entomol. 106(6): 2310-2321 (2013); DOI: http://dx.doi.org/10.1603/EC13092

\begin{abstract}
The South American tomato leafminer, Tuta absoluta Meyrick (Lepidoptera: Gelechiidae), is a major pest that has recently invaded Afro-Eurasia. Biological control, especially by Trichogramma parasitoids, is considered to be promising as a management tool for this pest. However, further development of Trichogramma-based biocontrol strategies would benefit from assessing the impact of released parasitoid offspring on the pest. Under laboratory conditions, we 1) compared the parasitism of five Trichogramma species-strains on the pest-plant system T. absoluta-tomato, and 2) assessed various biological traits of parasitoids, mass-reared on a factitious host (Ephestia kuehniella Zeller), when developing on T. absoluta. In addition, we evaluated the overall efficiency of two specific Trichogramma species when released under greenhouse conditions in combination with a common natural enemy in tomato crop, the predator Macrolophus pygmaeus Rambur. Parasitoids emerging from T. absoluta on tomato showed lower parasitism rates and poor biological traits, for example, wing deformations, reduced longevity, when compared with the control reared on the factitious host. Under greenhouse conditions, the parasitoids that developed on T. absoluta after initial releases contributed little to biological control of T. absoluta, and parasitism tended to be lower when the predator was present. However, a slightly higher T. absoluta control level was achieved by combining the predator and release of the parasitoid Trichogramma achaeae Nagaraja and Nagarkatti. This study shows that Trichogramma parasitoids may not build up populations on the T. absoluta-tomato system, but that Trichogramma parasitoids can be used in combination with M. pygmaeus to enhance biological control of the pest in tomato crops.
\end{abstract}

KEY WORDS fitness, generalist predator, invasive species, inundative release, mass-rearing

The South American tomato leafminer, Tuta absoluta Meyrick (Lepidoptera: Gelechiidae), is one of the most devastating tomato pests in South America (Gontijo et al. 2013). The pest has recently invaded and spread in the Afro-Eurasian continent, and in few years has become a major pest in tomato crops (Desneux et al. 2010, 2011a). Appearance of T. $a b$ soluta has led to extensive insecticide use by tomato growers, potentially causing a multitude of undesired side effects on nontarget organisms (Desneux et al. 2007; Arnó and Gabarra 2011; Biondi et al. 2012, 2013a). Among possible management methods currently studied (Amer et al. 2012, Cagnotti et al. 2012, Caparros Megido et al. 2012, Cocco et al. 2013), bio-

\footnotetext{
${ }^{1}$ French National Institute for Agricultural Research (INRA), ISA, 400 Route des Chappes, 06903 Sophia-Antipolis, France.

${ }_{2}^{2}$ InVivo AgroSolutions, 83 avenue de la Grande Armée, 75782 Paris, France.

${ }^{3}$ Corresponding author, e-mail: chailleux.anais@gmail.com.

${ }^{4}$ Department of Agri-Food and Environmental Systems Management, University of Catania, Via Santa Sofia 100, 95123 Catania, Italy.

${ }^{5}$ French National Institute for Agricultural Research (INRA), UEFM, 90 Chemin Gustave Raymond, 06160 Antibes, France.
}

logical control is considered for the development of environmentally and economically sound pest management tools for this pest in Europe (Desneux et al. 2010, Zappalà et al. 2013). Agricultural pests are largely controlled via top-down influences of natural enemies in a wide range of agro-ecosystems (van Driesche and Bellows 1996, Hawkins et al. 1997, Symondson et al. 2002, Lu et al. 2012). However, their use as biocontrol agents, either through augmentation or conservation biological control, is often slowed down because their effectiveness in the field is difficult to predict.

Parasitoids belonging to the Trichogramma genus (Hymenoptera: Trichogrammatidae) are generalist egg parasitoids, mainly of Lepidoptera. They are frequently used in biological control programs, notably through inundative releases (Smith 1996, Pintureau 2009, Mills 2010). In addition, inoculative releases of Trichogrammatids have been tested on agricultural pests in various crops (Thomson et al. 2003, Hoffmann et al. 2006, Mills 2010). In South America, T. absoluta is parasitized by Trichogramma pretiosum Riley under laboratory conditions (Pratissoli and Parra 2000), and 
Miranda et al. (1998) reported that nearly $10 \%$ of $T$. absoluta mortality occurring at the egg stage is because of natural parasitism by this parasitoid. Trichogrammatids have been used in tomato crops against $T$. absoluta through inundative releases both in the native (mainly with T. pretiosum; Parra and Zucchi 2004, Pratissoli et al. 2005) and the invaded areas (with Trichogramma achaeae Nagaraja and Nagarkatti; Cabello et al. 2012, Calvo et al. 2012). Considering the effectiveness of these programs and the natural parasitism of this pest by Trichogrammatids in South America and in Europe (Desneux et al. 2010, Zappalà et al. 2012, Biondi et al. 2013b), screenings for more effective species in the invaded area are ongoing (Chailleux et al. 2012, Khanh et al. 2012).

Various factors can influence the impact of inundative releases of mass-reared parasitoids. For instance, host selection by parasitoids may be influenced by the characteristics of both the host and host plant (Chau and Mackauer 2001, Desneux and RamirezRomero 2009). In addition, host preference in parasitoids tends to correlate with the fitness gained from the host (van Alphen and Vet 1986, Driessen et al. 1991, Chau and Mackauer 2001), this being defined as the "preference-performance" hypothesis (Jaenike 1978, Desneux et al. 2009b). However, very-low quality hosts can also be parasitized (Janssen 1989; Heimpel et al. 2003; Desneux et al. 2009a, 2012). Studies on acceptance of Trichogramma reared on factitious host species toward natural hosts yielded variable results. El-Wakeil (2007) showed differences in pest parasitism, which depended on the rearing host. The size of the natal host affected natural host parasitism rates in the field, and female parasitoids usually accepted host eggs of the same size or larger as their natal host (Salt 1940, Nurindah et al. 1999). By contrast, Kolliker-Ott et al. (2003) reported no preference-performance relationship for Trichogramma brassicae Bezdenko massreared on the factitious host Ephestia kuehniella Zeller when parasitizing the target host, the European corn borer Ostrinia nubilalis Hübner (Lepidoptera: Pyralidae).

The effectiveness of Trichogramma releases may depend not only on the biological characteristics of the parasitoid species or strains used, but also on their interactions with a specific pest-plant system (Tabone et al. 2010, Andrade et al. 2011, Yuan et al. 2012). Depending on the affinity of the parasitoids with the pest-plant system, the biocontrol services provided by the released parasitoids most likely vary. Trichogramma are mainly used as biocontrol agent through inundative releases, but the impact of Trichogramma generations developing within a crop can play a crucial role in the success of biological control programs (Mills 2010). For example, use of T. brassicae for biological control of the European corn borer in maize takes into account the effect of parasitoids developing in the field for the long-term control of the pest (Pintureau 2009). Additional mass-releases may be reduced and overall crop protection costs can be lowered.
To document the possible biocontrol impact of five Trichogramma species or strains, hereafter named "strains," when developing on T. absoluta eggs in the tomato crops after inundative releases, we evaluated their parasitism and the subsequent development of their offspring. Thus, in a first experiment, in the laboratory, we compared 1) a "released generation": developed in E. kuehniella eggs and offered T. absoluta eggs, with 2) a "field generation": developed in $T$. absoluta eggs and offered T. absoluta eggs, and a control treatment: parasitoids developed in E. kuehniella eggs and offered E. kuehniella eggs. This aimed at assessing possible reduced parasitoid performance when parasitoids switched from the mass-rearing host to the targeted pest-plant system. In a second experiment, in greenhouse, we tested the overall efficiency of caged release and the subsequent generation (that corresponds to the field generation) of two Trichogramma strains against $T$. absoluta. In addition, to assess the usefulness of Trichogramma parasitoids within the framework of current biocontrol programs in tomato crops in Europe, we included the predator $M a$ crolophus pygmaeus Rambur (Hemiptera: Miridae) in the greenhouse experiment because it is widely used for biocontrol of whiteflies on tomato, and is also released against $T$. absoluta because it preys on eggs (Desneux et al. 2010, Bompard et al. 2013).

\section{Materials and Methods}

Biological Materials. The plants used in the experiments were tomato plants, Solanum lycopersicum L. 'Marmande,' 5 wk old for the laboratory experiment and $7 \mathrm{wk}$ old for the cage experiment. Plants were grown in climatic chambers $\left(25 \pm 1{ }^{\circ} \mathrm{C}, 65 \%\right.$ relative humidity [RH], and a photoperiod of 16:8 [L:D] h); pesticide applications were strictly avoided, and a nutrient solution was applied daily. A colony of $T$. $a b$ soluta was set up using greenhouse-collected individuals in July of 2009 (initial number of individuals = 190) at the French National Institute for Agricultural Research (INRA), Alenya, France. T. absoluta was reared in growth chambers $\left(25 \pm 1^{\circ} \mathrm{C}, 70 \pm 10 \% \mathrm{RH}\right.$, and a photoperiod of 16:8 [L:D] h) in mesh netting cages ( 55 by 75 by $80 \mathrm{~cm}$ ) containing potted tomato plants (see Biondi et al. 2013c). Adult moths were fed on honey placed on the mesh inside the cages and on the plant. The parasitoids used for the experiments originated from collections (Table 1). Dr. B. Pintureau (INRA, Lyon, France) identified the species before the experiments, and voucher specimens were deposited at the INRA (Sophia-Antipolis, France). Trichogramma euproctidis Girault, and both Trichogramma evanescens Westwood strains were chosen because they were shown to be promising strains for biocontrol of T. absoluta during a previous study (29 strains tested, Chailleux et al. 2012). T. pretiosum was considered because it is mass reared and released to control this pest in South America. T. achaeae was tested because it has already been commercialized in Europe and Africa against T. absoluta. Colonies of parasitoids were reared on ultraviolet-irradiated eggs of a substi- 
Table 1. Country of origin, initial host plant, and host and year of collection of the five Trichogramma strains tested

\begin{tabular}{lllc}
\hline \multicolumn{1}{c}{ Species } & Geographic origin & Host plant & Most species \\
\hline T. achaeae Nagaraja and Nagarkatti, 1969 & Canaries islands & Tomato & Chrysodeixis chalcites \\
T. euproctidis Girault, 1911 & Switzerland & - & - \\
T. evanescens Westwood, 1833 (1) & Northern France & Vine & Lobesia botrana \\
T. evanescens Westwood, 1833 (2) & Northern France & Cauliflower & Argyrotaenia sphaleropa \\
T. pretiosum Riley, 1876 & Uruguay & Vine & Argyrotaenia sphaleropa \\
\hline
\end{tabular}

tute host, E. kuehniella $\left(18 \pm 1^{\circ} \mathrm{C}, 70 \pm 10 \% \mathrm{RH}\right.$, and a photoperiod of 12:12 [L:D] h), until used in the experiments. Rearing was carried out in glass tubes (4.5 $\mathrm{cm}$ in length and $0.7 \mathrm{~cm}$ in diameter), and the parasitoids were fed on honey droplets. E. kuehniella eggs were glued on a piece of cardboard ( 3 by $10 \mathrm{~mm}$ ) with $10 \%$ arabic gum (Pizzol et al. 2010). Parasitoids were maintained for at least three generations at the temperature of $25^{\circ} \mathrm{C}$ on $\mathrm{E}$. kuehniella eggs before starting experiments.

In the laboratory trials, the T. absoluta eggs used were $0-12 \mathrm{~h}$ old, and the parasitoids were $0-24 \mathrm{~h}$ old (as both host and parasitoid ages can play a role in development of the Trichogramma offspring, see Pizzol et al. 2012). To obtain parasitoid females that had developed in E. kuehniella eggs, females from the colonies were released on E. kuehniella eggs in the same conditions as described for the rearing, but female emergence date was checked precisely. Parasitoid females developed on T. absoluta eggs were obtained by releasing parasitoids from the colonies on T. absoluta eggs on tomato leaflets for $12 \mathrm{~h}$ inside ventilated Plexiglas tubes $(4 \mathrm{~cm}$ in diameter and $14 \mathrm{~cm}$ in length). The parasitoids used in all the experiments were collected daily from these tubes, namely those containing parasitized eggs of E. kuehniella or T. absoluta. M. pygmaeus specimens for the greenhouse experiment were reared on E. kuehniella eggs on artificial substrate by the private company Biotop (Valbonne, France) and after being purchased, they were reared for at least two generations in the laboratory. Rearing was carried out in cages ( 55 by 75 by $80 \mathrm{~cm}$ ) covered with a mesh in climatic chambers $\left(23 \pm 1^{\circ} \mathrm{C}, 70 \pm 5 \% \mathrm{RH}\right.$, and a photoperiod of 16:8 [L:D] h) on tobacco plant, and $E$. kuehniella eggs were provided ad libitum. New eggs were added twice a week, and tobacco plants were changed monthly. Adult predators used in the experiments were $1-3 \mathrm{~d}$ old.

Impact of T. absoluta-Tomato Pest-Plant System on Parasitism and Offspring Development. The experiment was conducted in growth chambers $\left(25^{\circ} \mathrm{C}\right.$, $70 \pm 10 \% \mathrm{RH}$, and a photoperiod of 16:8 [L:D] h). Two different combinations were tested mimicking the development of two generations of Trichogramma and the rearing situation (control treatment): 1) the released generation (developed in E. kuehniella eggs on cardboard and offered T. absoluta eggs on tomato leaflets), 2) the field generation (developed in T. $a b$ soluta eggs on tomato leaflets and offered T. absoluta eggs on tomato leaflets), and 3) parasitoids in the rearing situation were used as a control. Control individuals developed on E. kuehniella eggs and were offered E. kuehniella eggs on cardboard.
Control (Treatment 3) and Released Generations (Treatment 1). Females emerging from E. kuehniella eggs (obtained as described in the "Biological Materials" section) were used both for the control treatment, when releasing the females on E. kuehniella eggs, and for the released generation treatment, when releasing the female on T. absoluta eggs. Therefore, young mated females were released individually in glass tube containing 30-40 eggs of E. kuehniella (the same technique as previously described for the rearing) and fed with honey droplets during $24 \mathrm{~h}$ to measure the control ("rearing generation") parameters. However, for the released generation, young mated females were presented individually with 30-40 T. absoluta eggs on a tomato leaflet in ventilated Plexiglas tubes $(4 \mathrm{~cm}$ in diameter and $14 \mathrm{~cm}$ in length) with honey during $24 \mathrm{~h}$. The stems of leaflet, sticking out of the tube, were planted into floral foam for watering.

Field Generations (Treatment 2). To evaluate the field generation parameters, young Trichogramma females emerging from T. absoluta-parasitized eggs (obtained as described in the "Biological Materials" section) were presented individually to $30-40 \mathrm{~T}$. absoluta eggs on a tomato leaflet in the ventilated tube (with honey droplets as food source) during $24 \mathrm{~h}$. Thus, we used the same oviposition conditions as the released generation, except that females had previously developed in T. absoluta eggs vs. E. kuehniella eggs.

For the three treatments, tubes containing parasitized eggs were kept in a climatic chamber $\left(25^{\circ} \mathrm{C}, 70 \pm\right.$ $10 \% \mathrm{RH}$, and a photoperiod of 16:8 [L:D] h) and maintained until offspring emergence for $15 \mathrm{~d}$. For each treatment, the number of parasitized eggs (black eggs) and of aborted eggs (white and unhatched eggs) was counted after $5 \mathrm{~d}$ of parasitization. The sex ratio (females per total) and the wings deformation occurrence (absent, stump, or crumple wings) of offspring individuals (F1) were recorded $2 \mathrm{~d}$ after emergence, namely $15 \mathrm{~d}$ after the parasitization. Ten to 15 replicates were carried out per parasitoid strain and per treatment.

Impact of the Host on the Longevity. We assessed the longevity of female parasitoids that had developed in T. absoluta eggs (=the field generation) and in $E$. kuehniella eggs as a control. Females were obtained as described in the "Biological Materials" section. These were placed in glass tubes $(4.5 \mathrm{~cm}$ in length and $0.7 \mathrm{~cm}$ in diameter), closed with a cotton ball and provided with honey or left without in climatic chambers $\left(25^{\circ} \mathrm{C}\right.$, $70 \pm 10 \% \mathrm{RH}$, and a photoperiod of 16:8 [L:D] h). Twenty to 25 females per strain and per rearing host were tested. The survival was checked daily with a binocular microscope, and parasitoids were consid- 
ered dead when they did not react after being touched by a fine paint brush.

Cage Experiment. A cage experiment was carried out with the aim of testing the efficiency of the field generation under realistic conditions. The experiment was carried out in cages $(100 \mathrm{~cm}$ in height, $70 \mathrm{~cm}$ in width, and $100 \mathrm{~cm}$ in length, made with insect-proof mesh) that were placed in a greenhouse at the INRA Sophia AgroBiotech Institute (Sophia-Antipolis, France). The greenhouse was similar to the ones used by many tomato growers in France and more broadly in Southern Europe (semicontrolled temperatures, min $<$ mean temperature $<$ max: $15.5<24.2<37.4^{\circ} \mathrm{C}$; $\min <$ mean $\mathrm{RH}<\max , 18.0<63.0<90.0 \%$; natural ambient light: mid-July mid-August 2011). The two Trichogramma species tested, T. achaeae and T. euproctidis, which showed the highest parasitism at the field generation in the laboratory (see "Results" section), were chosen for this experiment. Both species were tested alone and in combination with the predator M. pygmaeus. The predator was also tested alone and a control with the pest alone was carried out. The following six treatments or combinations were studied: 1) T. absoluta, 2) T. absoluta + M. pygmaeus, 3) T. absoluta + T. achaeae, 4) T. absoluta + T. euproctidis, 5) T. absoluta + T. achaeae + M. pygmaeus, and 6) T. absoluta + T. euproctidis + M. pygmaeus. The experiment lasted $16 \mathrm{~d}$ to allow first field generation observation, and six replicates (cages) were carried out per treatment.

Eight tomato plants (development stage from seven to eight fully expanded leaves) were placed into the cages. First, 22-d-old T. absoluta adults (10 males and 10 females) were released per cage. After $24 \mathrm{~h}$, predators, parasitoids, or both, were introduced into the cages. Depending on the treatment, 400 Trichogramma adults and eight pairs of M. pygmaeus (1:1, male/female) were released. These release rates were chosen according to the recommendations of producers of natural enemies. To release Trichogramma parasitoids, we mimicked a field release similar to what is recommended by the producers. One open glass tube containing a small cardboard strip bearing 400 parasitized E. kuehniella eggs was placed in the center of each cage. Honey droplets were provided as food source to the parasitoids. A quality control carried out on a sample of 1,000 parasitized eggs per parasitoid strain (randomly selected from the stock of parasitized eggs used in this experiment) showed that parasitoid emergence was always $>90 \%$. Individuals showed a sex ratio of $\approx 0.70$ (females/total) for both species. Therefore, we assumed that releasing 400 parasitized eggs corresponded to a release of $\approx 252$ parasitoid females.

To facilitate the parasitization monitoring, we added four sentinel tomato leaflets bearing $30 \mathrm{~T}$. $a b$ soluta eggs ( 15 on adaxial and 15 on abaxial surfaces of each leaflet) before the parasitoids release. These leaflets were placed on the top of a stake so that they always touched a tomato leaf in the upper plant part. The stems of these leaflets were put inside a tube full of water. Five days later, leaflets were collected and parasitized eggs (black eggs) and predated eggs (empty crumpled eggs) were counted under a binocular microscope and percent parasitism and percent predation rates were calculated. Then, the leaflets were put back inside their respective cages.

To evaluate parameters in the same way for the field generation, produced by the released parasitoid, we provided new sentinel leaflet at the field generation emergence time. The Trichogramma juveniles (egg to adult) developmental time is $8 \mathrm{~d}$ at $30^{\circ} \mathrm{C}$ (Foerster and Foerster 2009); therefore, the new leaflets were placed in each cage $8 \mathrm{~d}$ after the Trichogramma releases, following the same procedure previously described. The leaflets were collected $7 \mathrm{~d}$ later to enable an effective assessment of overall parasitism undertaken by the second-generation parasitoid females, as they emerged for up to $3 \mathrm{~d}$ and adults longevity in greenhouse conditions is $\leq 3 \mathrm{~d}$ (A. C. and N. D., unpublished data). Parasitized eggs and predated eggs were counted under a binocular microscope as for the released generation. Plants were destructively sampled at the end of the experiment (after $16 \mathrm{~d}$ ). The number of T. absoluta larvae and M. pygmaeus juveniles were counted in each cage on four plants chosen randomly.

Statistical Analyses. All statistical analyses were performed using the R software with the multcomp and agricolae packages. For the laboratory experiments, the number of parasitized and aborted eggs were analyzed using a generalized linear model (GLM) based on Poisson distributed data with a log link function. Sex ratio (females per total) and wing malformations were analyzed using a GLM designed for modeling binomial data with a logit link function. For these four parameters the effect of the factors Rearing host (host egg used to rear parasitoid), Oviposition host (host egg parasitized by the females in the experiments), and Trichogramma strain were tested. Longevity was also analyzed using a GLM, but it was designed for modeling gamma data with an inverse link function. The effect of the factors Rearing host, Honey supply, and Trichogramma strain were tested.

For the cage experiments, the percentages of parasitism, aborted eggs, and predated eggs were analyzed using a GLM designed for modeling binomial data. For the parasitism and aborted eggs, the effect of the factors, M. pygmaeus, Trichogramma generation (released or field generations) and Trichogramma strain factors were tested. For the predated eggs the effect of the factors Trichogramma strain and Trichogramma generation were tested. A GLM designed for Poisson distributed data were used to analyze the number of T. absoluta larvae and M. pygmaeus juveniles. For T. absoluta larvae, the factor Trichogramma strain and M. pygmaeus were tested, and for the $M$. pygmaeus juvenile, the Trichogramma strain factor was tested. Finally, multiple comparisons were performed using a Fisher least significant difference (LSD) post hoc test for both laboratory and cage experiments. 


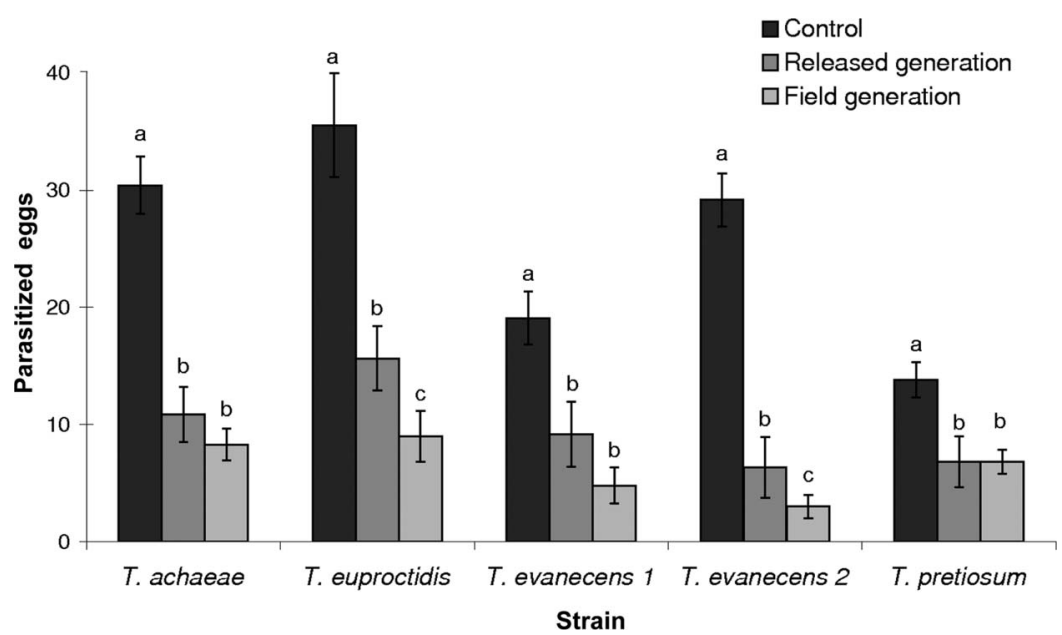

Fig. 1. Mean $( \pm$ SEM) number of parasitized eggs per parasitoid female for the five Trichogramma strains tested. Released generation: developed in E. kuehniella eggs and offered T. absoluta eggs; field generation: developed in T. absoluta eggs and offered T. absoluta eggs; control: developed in E. kuehniella eggs and offered E. kuehniella eggs. Post hoc tests (Fisher LSD test) were carried out separately for each strain tested. For each generation tested (released and field generations) and for the control, the histograms bearing the same letter are not significantly different at $P<0.05$.

\section{Results}

Impact of T. absoluta-Tomato Pest-Plant System on Parasitism and Offspring Development. There was a significant effect of the Rearing host (host in which ovipositing parasitoid developed; $F_{(1,181)}=80.980 ; P<$ 0.001 ) and of the Oviposition host (host parasitized in the experiment; $\left.F_{(1,182)}=91.780 ; P<0.001\right)$ on the number of parasitized eggs. Parasitism also varied significantly among the Trichogramma strains $\left(F_{(4,177)}=\right.$ 8.902; $P<0.001)$. The number of parasitized eggs ranged from $35.5 \pm 4.4$ for the rearing generation of $T$. euproctidis to $3.0 \pm 1.0$ for the field generation of $T$. evanescens 2 (Fig. 1). Parasitism of all the strains was significantly lower when females were offered T. $a b$ soluta (released and field generations) than E. kuehniella eggs (control). Parasitism rates of T. euproctidis and T. evanescens 2 were also lower when females had developed on T. absoluta (field generation) than when females had developed on E. kuehniella eggs (control and released generation; Fig. 1).

The host egg species in which the females developed (Rearing host) significantly affected the sex ratio of their offspring (Fig. $2 ; F_{(1,127)}=5.149 ; P<0.025$ ). Indeed, the T. achaeae field generation was more male-

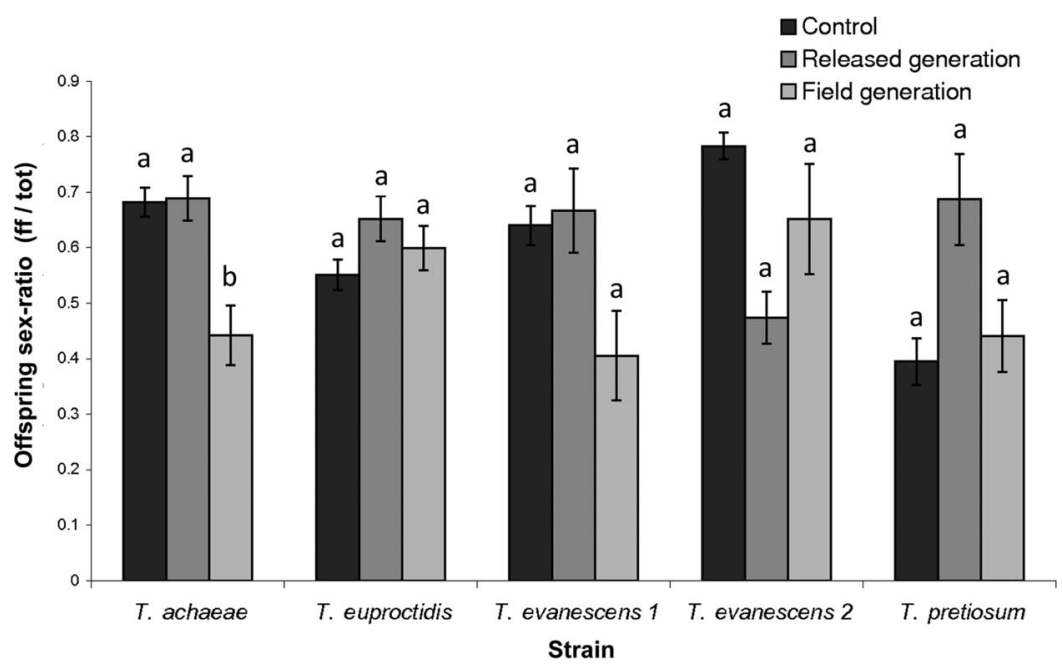

Fig. 2. Mean sex ratio ( \pm SE; females per total) of offspring for the five Trichogramma strains tested. Released generation: females developed in E. kuehniella eggs and offered T. absoluta eggs; field generation: females developed in T. absoluta eggs and offered T. absoluta eggs; control: females developed in E. kuehniella eggs and offered E. kuehniella eggs. Post hoc tests (Fisher LSD test) were carried out separately for each strain tested. For each generation tested (released and field generations) and for the control, the histograms bearing the same letter are not significantly different at $P<0.05$. 


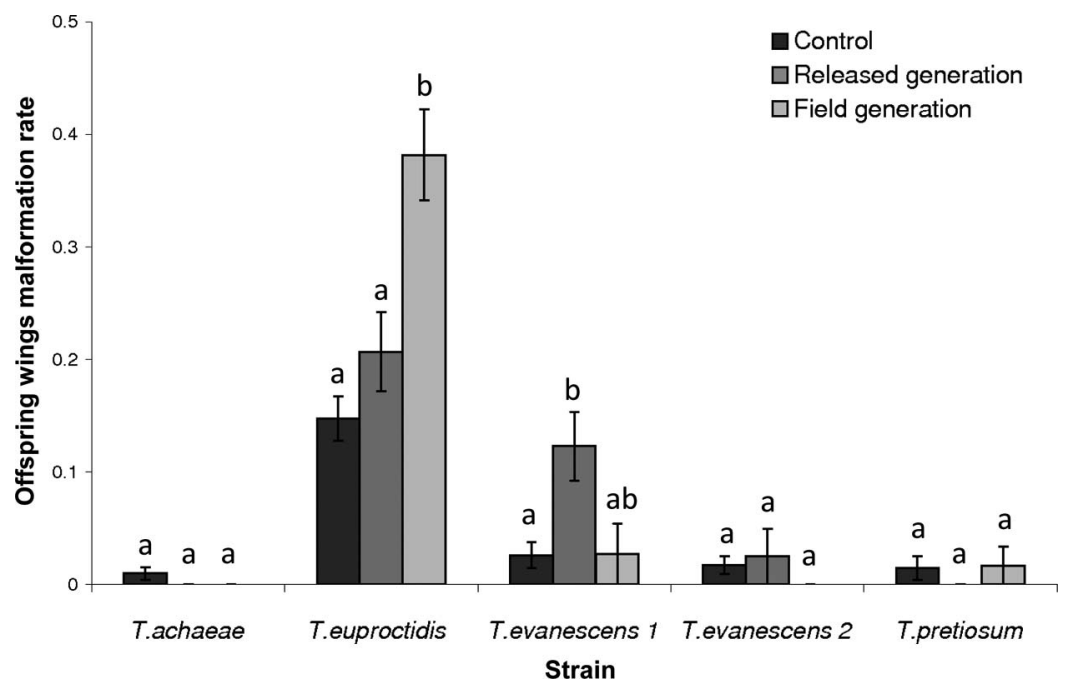

Fig. 3. Proportion $( \pm \mathrm{SE})$ of offspring with wings malformation: absent, stump, or crumple wings, for the five Trichogramma strains tested. Released generation: females developed in E. kuehniella eggs and offered T. absoluta eggs; field generation: females developed in T. absoluta eggs and offered T. absoluta eggs; control: females developed in E. kuehniella eggs and offered E. kuehniella eggs. Post hoc tests (Fisher LSD test) were carried out separately for each strain tested. For each generation tested (released and field generations) and for the control, the histograms bearing the same letter are not significantly different at $P<0.05$.

biased than its generations developing on E. kuehniella eggs. By contrast, the Oviposition host factor did not significantly affect the sex ratio $\left(F_{(1,126)}=0.0736 ; P<\right.$ $0.787)$. The sex ratio of the offspring also varied significantly among strains tested (significant Trichogramma strain factor; $\left.F_{(4,122)}=4.937 ; P<0.001\right)$. The sex ratio significantly differed among generations only in the case of $T$. achaeae when strains were tested individually (Fig. 2; Fisher LSD test). The sex ratio of offspring from the field generation was significantly lower than in the two other treatments (control and released generation). We observed similar trends for T. evanescens 1 (Fig. 2), but differences among treatment were not significant either for T. evanescens 1 or the three other strains (most likely owing to a low number of offspring individuals in the field generation).

Trichogramma strain, Rearing host, and Oviposition host factors all had a significant impact on wing malformations occurring in offspring $\left(F_{(4,122)}=39.107\right.$; $P<0.001 ; F_{(1,127)}=24.765 ; P<0.001 ; F_{(1,126)}=7.479$; $P=0.007$, respectively). The strain presenting the highest proportion of offspring with malformed wings was T. euproctidis (Fig. 3), the highest proportion was observed for the T. euproctidis field generation, with $38 \pm 4 \%$ of offspring with wing malformations (Fig. 3).

Impact of the Host System on the Longevity. The effects of the Rearing host $\left(\chi^{2}=173.319\right.$; $\mathrm{df}=1 ; P<$ $0.001)$ and the Honey supply factors $\left(\chi^{2}=173.319\right.$; $\mathrm{df}=1 ; P<0.001)$ were significant on female parasitoid longevity (Fig. 4). The Trichogramma strain factor also had a significant effect on Trichogramma longevity $\left(\chi^{2}=28.530 ; \mathrm{df}=4 ; P<0.001\right)$, with a maximum of $18 \mathrm{~d}$ on average for T. evanescens 1 developed in E. kuehniella egg and supplied with honey (Fig. 4A). Without honey, longevity did not exceed $4 \mathrm{~d}$ (for T. pretiosum emerged from E. kuehniella eggs; Fig. 4B).

Cage Experiment. Trichogramma strain and M. pygmaeus had significant effects on the percentage of parasitism observed on the sentinel leaflets (Fig. 5; $F_{(1,29)}=22.648 ; P<0.001$ and $F_{(1,30)}=8.981 ; P=$ 0.007 , respectively). The parasitism of the field generation was significantly lower than of the released generation $\left(F_{(1,28)}=33.542 ; P<0.001\right)$. The highest level of percent parasitism was obtained with $T$. achaeae alone. On the contrary, no parasitism was observed for the field generation of T. euproctidis in the presence of M. pygmaeus (Fig. 5).

In the three treatments with M. pygmaeus, the number of eggs eaten did not vary significantly depending on the Trichogramma strain (T. achaeae or T. euproctidis or absence) $\left(F_{(2,21)}=0.080 ; P=0.923\right)$. No significant effect of the Trichogramma generation factor (released, field generations) was observed $\left(F_{(1,20)}=0.876 ; P=0.363\right) . T$. absoluta eggs were preyed on an average $71.7 \pm 3.6 \%$, ranged between 25 and $96.6 \%$. The factors Trichogramma strain ( $T$. achaeae, T. euproctidis or absence), M. pygmaeus, and Trichogramma generation had a significant effect on the number of aborted eggs $\left(F_{(2,44)}=3.918 ; P=0.029\right.$; $F_{(1,46)}=12.429 ; P=0.001 ;$ and $F_{(1,43)}=12.429 ; P=$ 0.001 , respectively). However, the overall percentages of aborted eggs were low throughout the course of the experiments in cages $(\leq 5 \%)$. The maximum values were observed in groups with Trichogramma parasitoids without $M$. pygmaeus (released generation).

At the end of the experiment, an overall average of $2.12 \pm 0.50 \mathrm{M}$. pygmaeus juveniles per plant was recorded, ranging from one to three per plant. No significant differences related to the Trichogramma pres- 


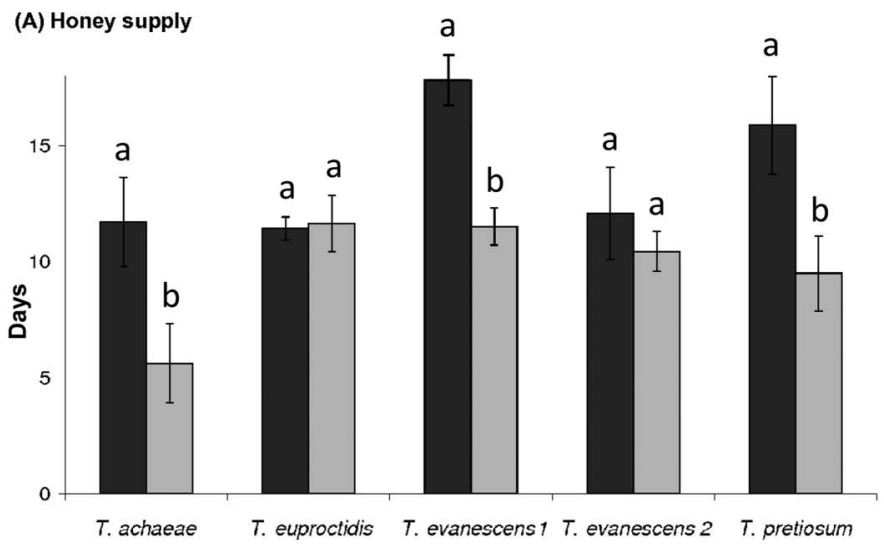

(B) No honey

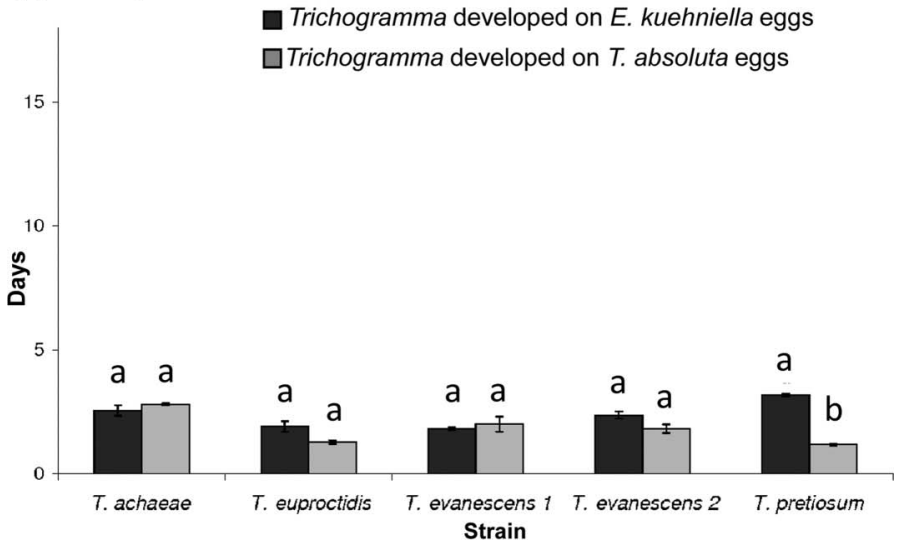

Fig. 4. Mean $( \pm \mathrm{SE})$ longevity of the five Trichogramma strains tested for females developed in E. kuehniella eggs (equivalent to the control and the released generation); and for females developed in T. absoluta eggs (equivalent to the field generation); (A) in presence of honey as food source and (B) without any food sources. Post hoc tests (Fisher LSD test) were carried out separately for each strain tested. For each emergence host tested the histograms bearing the same letter are not significantly different at $P<0.05$.

ence were observed $\left(F_{(2,9)}=0.022 ; P=0.978\right)$. The number of T. absoluta larvae was influenced by Trichogramma presence, though only numerically different (Fig. 6; $\left.F_{(2,21)}=2.870 ; P=0.086\right)$, and it was significantly affected by $M$. pygmaeus $\left(F_{(1,20)}=9.178 ; P=\right.$ $0.008)$. The highest number of larvae was obtained in the control (T. absoluta alone) and the lowest infestation was observed in the treatment combining $T$. achaeae and M. pygmaeus, although it was not significantly different from the treatments with $T$. achaeae alone and M. pygmaeus alone and with T. euproctidis (Fig. 6).

\section{Discussion}

The parasitism of five Trichogramma strains, belonging to four species, on T. absoluta was evaluated in the laboratory by testing two different parasitoid generations, particularly the ones potentially occurring in tomato crop after inundative releases of parasitoids. The parasitism of T. absoluta eggs on tomato by parasitoids from the released and field generations was related to the parasitism observed in individuals from a control treatment, which is reared in the laboratory on the factitious host E. kuehniella. The highest parasitism was recorded for the generations under the standard rearing conditions on the factitious host. Parasitism decreased when oviposition occurred on the novel pest-plant system. Among the three treatments, the lowest parasitism was recorded for the field generation although it was not consistent for T. euproctidis and T. pretiosum, which showed same parasitism levels in both released and field generations.

Overall, parasitism efficiency decreased on the $T$. absoluta-tomato system, so that this pest-plant system appeared unsuitable for the Trichogramma strains tested. Our results showed a decrease of female progeny sex ratio, increased malformations of individuals (deformed wings), and reduced longevity (for $T$. achaeae, T. evanescens 1 , and T. pretiosum, with up to a 6 -d reduction) in the pest-plant system studied compared with rearing conditions.

Plausibly, differences among parasitoid efficiency recorded for the control and the released and field generations are linked to host physiological suitability for the Trichogramma strains tested. Although the host 


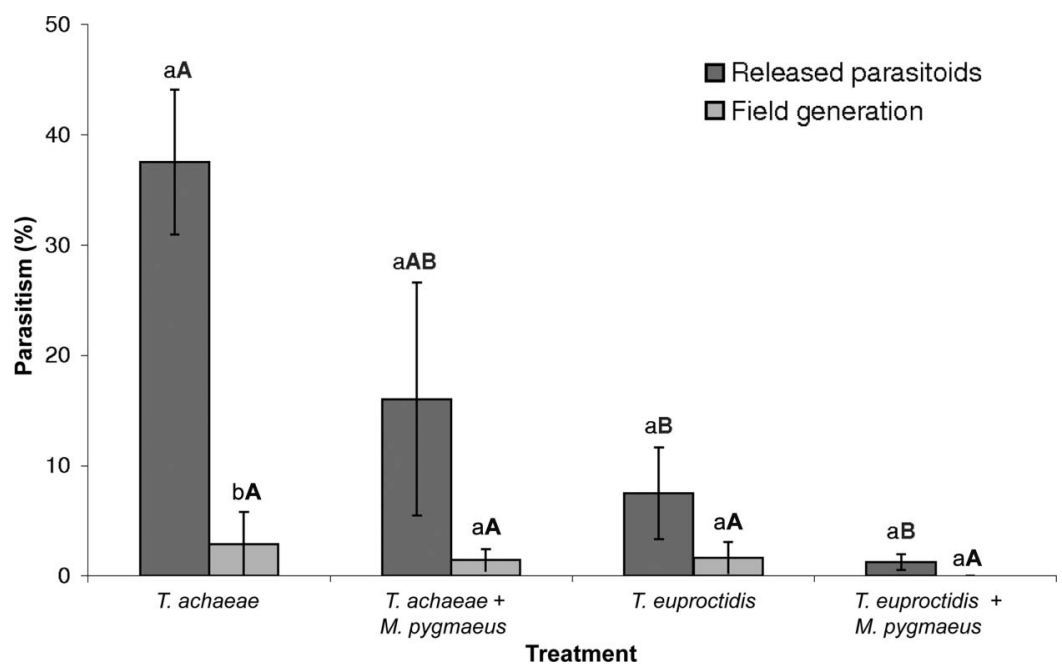

Fig. 5. Mean $( \pm \mathrm{SE})$ percent parasitism of T. absoluta eggs obtained on sentinel leaflets placed in greenhouse cages for the four treatments with Trichogramma releases, for the released generation (females developed in E. kuehniella eggs) and the field generation (females developed in T. absoluta eggs). Two types of post hoc tests (Fisher LSD test) have been done separately 1) each strain separately, generations bearing the same lowercase letters are not significantly different for $P<0.05$; and 2) each generation separately, strains bearing the same capital letters are not significantly different at $P<0.05$.

size-parasitoid fitness relationship is not always consistent among parasitoids species (Harvey et al. 2013), parasitoids largely depend on the quality and quantity of resources provided by the host for their larval development (Mackauer 1996, Pennacchio and Strand 2006). A close relationship has been generally observed between the size of the host parasitized and the size and fitness of parasitoid offspring, for example, egg load of emerging females (Harvey et al. 2013). In addition, offspring sex ratio and longevity can be linked to the size of parasitoid individual (Fidgen et al. 2000) and Trichogramma parasitoids commonly show preference for relatively large host eggs (Roriz et al. 2006). T. achaeae is reared on E. kuehniella eggs by producers of natural enemies, and eggs of this host are threefold larger than those of T. absoluta. Therefore, the decrease in parasitoids quality (parasitism efficiency, sex ratio, longevity, and wing malformations) that developed in T. absoluta eggs may result from the small size of the host eggs, for example, smaller parasitoids emerged from T. absoluta eggs (A. C., unpublished data). Wing malformations in Trichogramma have been documented in other studies. Wings and abdominal malformations were observed in Trichogramma parasitoids reared on artificial diet (Consoli and Parra 1996), and sexual dimorphism (apterous males and fully winged females) of $T$. semblidis was described by Salt (1937) when the parasitoids developed in small eggs (Sialis lutaria L. [Megaloptera: Sialidae]) vs. E. kuehniella eggs. Finally, we cannot

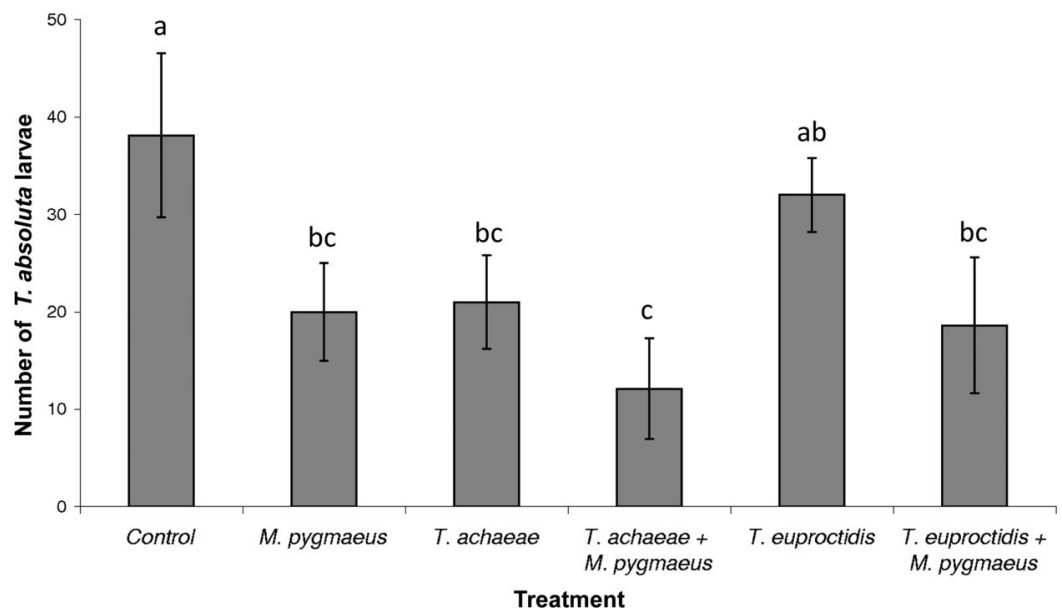

Fig. 6. Mean $( \pm \mathrm{SE})$ number of T. absoluta larvae per plant $16 \mathrm{~d}$ after insect releases in greenhouse cages for the six treatments tested. Values marked with the same letter do not differ significantly at $P<0.05$ (Fisher LSD test). 
exclude that parasitoid rearing, at least concerning Trichogramma for many generations on a factitious host, could have affected parasitoids capacity to attack other hosts (Hopper and Roush 1993, Hoffmann et al. 2001, Chailleux et al. 2012).

Understanding the suitability of the pest-plant system that underpins the parasitism pattern in the laboratory has important practical implications, as highlighted by our greenhouse cage experiments, where the parasitism activity of the field generation of both Trichogramma species was quite low in cages under greenhouse conditions. However, overall T. absoluta control achieved by T. achaeae was similar to those achieved with $M$. pygmaeus when these natural enemies were used alone $(\approx 46 \%$ decrease in $T$. absoluta larvae per plant, see Fig. 6), though the experiment was carried out over a short period as infestation levels were measured $16 \mathrm{~d}$ after the pest was introduced into the cages. As opposed to the results under laboratory conditions, T. euproctidis both released and field generations (with or without predator) showed the lowest parasitism rates in the greenhouse cage experiments. This species was not able to control T. absoluta populations; there was no significant difference in $T$. absoluta density compared with the control (see Fig. 6 ). These results indicate that populations of parasitoids released in the tomato crop may disappear soon after the releases. Therefore, the impact of Trichogramma field generation(s) on T. absoluta population growth could be considered negligible for biological control, at least with strains tested in our study.

This study further documents the possible impacts of Trichogramma generations when parasitoids emerged in the greenhouse from T. absolutaparasitized eggs. Poor effectiveness of the field generation parasitoid in T. absoluta parasitism may be because of various factors. First, continuous tomato plant growth during the course of the cage experiment has led most likely to an increasing plant architecture complexity between the beginning of the experiment, in which the parasitoids were first released (released generation), and the end of the experiment, when parasitoids developing in T. absoluta-parasitized eggs emerged. Increased habitat complexity is known to negatively affect efficiency (host searching, dispersal ability, or both) of natural enemies in finding hosts or prey (Rutledge and O'Neil 2005, Tabone et al. 2012). Second, parasitism effectiveness may have decreased because of 1) the small size of the parasitoids emerging from T. absoluta eggs (such small host eggs make parasitoid females mature fewer eggs, Kazmer and Luck 1995), and 2) increased sex ratio in offspring produced (more males in the population). Third, parasitoid mobility may have been reduced on tomato plants because of the high pubescence of tomato. Foraging ability was consequently reduced (Carrillo et al. 2008). Trichogramma parasitoids are known to be poor flyers and to forage primarily by walking and jumping on substrates (Keller 1987, Olson and Andow 2006). In addition, previous studies reported that tomato trichomes have negative effects on Tricho- gramma efficiency (Kauffman and Kennedy 1989, Farrar et al. 1994).

Our results suggest that the pest-plant system $T$. absoluta-tomato shows unfavorable characteristics for the effective establishment of Trichogramma parasitoids in tomato crops. This contrasts with other pestplant systems in which Trichogramma field parasitoid generations provide biocontrol services to some extent after the initial release in the crop, for example, on the European corn borer in maize crop (Thomson et al. 2003, Hoffmann et al. 2006, Pintureau 2009). Thus, the expected biocontrol service provided by the Trichogramma field generations in tomato crop against T. absoluta should be considered low. Trichogrammabased biocontrol programs targeting T. absoluta on tomato crop therefore may need to rely on periodical inundative releases of the parasitoid, at least for Trichogramma strains so far identified as potential natural enemies of T. absoluta in Europe.

We also evaluated the effect of the generalist predator M. pygmaeus presence on the effectiveness of $T$. achaeae and T. euproctidis releases against T. absoluta. $M$. pygmaeus decreased the abundance of parasitoids hence their effectiveness on T. absoluta, both through direct competition for the resource (moth eggs), and direct predation on Trichogramma-parasitized eggs (Desneux et al. 2011b, Chailleux et al. 2013). Parasitism exerted by the released and field generations on both parasitoid strains was lower when the predator was present. The highest T. absoluta control level ( $<68 \%$ larvae per plant than in the control) was achieved when combining the parasitoid T. achaeae with the predator, although it was not significantly different from T. achaeae or M. pygmaeus when tested alone. In addition, the presence of $M$. pygmaeus nymphs suggested effective predator establishment after introduction into cages. Previous studies reported that supplementary releases of T. achaeae in tomato crops, in which another mirid predator $(\mathrm{Ne}$ sidiocoris tenuis Reuter) was released during the cropping cycle, improved the biological control of T. $a b$ soluta (Desneux et al. 2010; Cabello et al. 2012). Our results back up these conclusions. However, additional releases of T. achaeae did not improve control of T. absoluta when $N$. tenuis was inoculated by preplant releases in nurseries (Calvo et al. 2012), namely when the predator populations were already well established in the tomato crop before arrival of T. absoluta. Nevertheless, such a strategy based on very early establishment of $N$. tenuis in nursery plants often leads to use of insecticides when the omnivorous predator reaches high densities. Indeed, this predator is known to inflict damage to tomato plants, causing necrotic rings on stems and flowers and punctures in fruits (Calvo et al. 2009, Castañé et al. 2011).

Our study suggests that the integration of Trichogramma parasitoids for biological control strategies against T. absoluta in tomato crops should rely on the use of several inundative releases and should also take into account the population levels of generalist predators either artificially released, naturally occurring in the tomato crop, or both. 


\section{Acknowledgments}

We thank Cécile Thomas, Philippe Bearez, and Etty-Ambre Colombel (INRA Sophia-Antipolis) for technical assistance; Méline Beal and Jacques Frandon (Biotop, InVivo AgroSolutions) for providing biological materials; ANRT (National Association of Research and Technology) and InVivo AgroSolutions for funding to A. C. (Ph.D. fellowship); the University of Catania for funding to A. B. (Ph.D. fellowship); the French ministry of agriculture for funding to N. D. (CASDAR [Account for Agricultural and Rural Development] project 10063); and the anonymous referees as well as the handling editor for their helpful comments.

\section{References Cited}

Amer, R.A.M., A. E. Hatem, and M. A. El-Sanady. 2012. Microbial control of the tomato leaf-miner, Tuta absoluta (Povolny) (Lepidoptera: Gelechiidae) by biopesticides in relation to some biological parameters. Egypt. J. Biol. Pest Control 22: 161-167.

Andrade, G. S., D. Pratissoli, L. P. Dalvi, N. Desneux, and H.J.G. dos Santos. 2011. Performance of four Trichogramma species (Hymenoptera: Trichogrammatidae) as biocontrol agents of Heliothis virescens (Lepidoptera: Noctuidae) under various temperature regimes. J. Pest Sci. 84: 313-320.

Arnó, J., and R. Gabarra. 2011. Side effects of selected insecticides on the Tuta absoluta (Lepidoptera: Gelechiidae) predators Macrolophus pygmaeus and Nesidiocoris tenuis (Hemiptera: Miridae). J. Pest Sci. 84: 513-520.

Biondi, A., N. Desneux, G. Siscaro, and L. Zappalà. 2012. Using organic-certified rather than synthetic pesticides may not be safer for biological control agents: selectivity and side effects of 14 pesticides on the predator Orius laevigatus. Chemosphere 87: 803-812.

Biondi A., L. Zappalà, J. D. Stark, and N. Desneux. 2013a. Do biopesticides affect the demographic traits of a parasitoid wasp and its biocontrol services through sublethal effects? Plos ONE 8(9): e76548. doi:10.1371/journal. pone.0076548.

Biondi, A., A. Chailleux, J. Lambion, P. Han, L. Zappalà, and N. Desneux. 2013b. Indigenous natural enemies attacking Tuta absoluta (Lepidoptera: Gelechiidae) in Southern France. Egypt. J. Biol. Pest Control 23: 117-121.

Biondi, A., N. Desneux, E. Amiens-Desneux, G. Siscaro, and L. Zappalà. 2013c. Biology and developmental strategies of the Palaearctic parasitoid Bracon nigricans (Hymenoptera: Braconidae) on the Neotropical moth Tuta absoluta (Lepidoptera: Gelechiidae). J. Econ. Entomol. 106: 16381647.

Bompard, A., C. Jaworski, P. Bearez, and N. Desneux. 2013. Sharing a predator: can an invasive alien pest affect the predation on a local pest? Soc. Popul. Ecol. 55: 433-440.

Cabello, T., J. R. Gallego, F. J. Fernandez, M. Gamez, E. Vila, M. Del Pino, and E. Hernandez. 2012. Biological control strategies for the South American tomato moth (Lepidoptera: Gelechiidae) in greenhouse tomatoes. J. Econ. Entomol. 105: 2085-2096.

Calvo, J., K. Blockmans, P. A. Stansly, and A. Urbaneja. 2009. Predation by Nesidiocoris tenuis on Bemisia tabaci and injury to tomato. Biocontrol 54: 237-246.

Calvo, F. J., M. J. Lorente, P. A. Stansly, and J. E. Belda. 2012. Preplant release of Nesidiocoris tenuis and supplementary tactics for control of Tuta absoluta and Bemisa tabaci in greenhouse tomato. Entomol. Exp. Appl. 143: 111-119.

Cagnotti, C. L., M. M. Viscarret, M. B. Riquelme, E. N. Botto, L. Z. Carabajal, D. F. Segura, and S. N. López. 2012.
Effects of X-rays on Tuta absoluta for use in inherited sterility programmes. J. Pest Sci. 85: 413-421.

Caparros Megido, R., E. Haubruge, and F. J. Verheggen. 2012. First evidence of deuterotokous parthenogenesis in the tomato leafminer, Tuta absoluta (Meyrick) (Lepidoptera: Gelechiidae). J. Pest Sci. 85: 409-412.

Carrillo, D., J. E. Pena, and J. L. Capinera. 2008. Effect of host plants on successful parasitism by Haeckeliania sperata (Hymenoptera: Trichogrammatidae) on Diaprepes abbreviatus (Coleoptera: Curculionidae) Eggs. Environ. Entomol. 37: 1565-1572.

Castañé, C., J. Arno, R. Gabarra, and O. Alomar. 2011. Plant damage to vegetable crops by zoophytophagous mirid predators. Biol. Control 59: 22-29.

Chailleux A., N. Desneux, J. Seguret, H. Do Thi Khanh, P. Maignet, and E. Tabone. 2012. Assessing European Egg parasitoids as a mean of controlling the invasive South American tomato pinworm Tuta absoluta. Plos ONE 7: e48068. (doi: http://dx.doi.org/10.1371/journal.pone.0048068).

Chailleux, A., J. Pizzol, E. Amiens-Desneux, R. RamirezRomero, and N. Desneux. 2013. Potential for combining indigenous natural enemies for biological control of the key invasive tomato pest, Tuta absoluta, in Afro-Eurasia. J. Pest Sci. 86: 533-541.

Chau, A., and M. Mackauer. 2001. Host-instar selection in the aphid parasitoid Monoctonus paulensis (Hymenoptera: Braconidae, Aphidiinae): assessing costs and benefits. Can. Entomol. 133: 549-564.

Cocco, A., S. Deliperi, and G. Delrio. 2013. Control of Tuta absoluta (Meyrick) (Lepidoptera: Gelechiidae) in greenhouse tomato crops using the mating disruption technique. J. Appl. Entomol. 137: 16-28.

Consoli, F. L., and J.R.P. Parra. 1996. Biology of Trichogramma galloi and T. pretiosum (Hymenoptera: Trichogrammatidae) reared in vitro and in vivo. Ann. Entomol. Soc. Am. 89: 828-834.

Desneux, N., and R. Ramirez-Romero. 2009. Plant characteristics mediated by growing conditions can impact parasitoid's ability to attack host aphids in winter canola. J. Pest Sci. 82: 335-342.

Desneux, N., A. Decourtye, and J. M. Delpuech. 2007. The sublethal effects of pesticides on beneficial arthropods. Annu. Rev. Entomol. 52: 81-106.

Desneux, N., P. Stary, C. J. Delebecque, T. D. Gariepy, R. J. Barta, K. A. Hoelmer, and G. E. Heımpel. 2009a. Cryptic species of parasitoids attacking the Soybean Aphid (Hemiptera: Aphididae) in Asia: Binodoxys communis and Binodoxys koreanus (Hymenoptera: Braconidae: Aphidiinae). Ann. Entomol. Soc. Am. 102: 925-936.

Desneux, N., R. J. Barta, K. A. Hoelmer, K. R. Hopper, and G. E. Heimpel. 2009b. Multifaceted determinants of host specificity in an aphid parasitoid. Oecologia 160: 387-398.

Desneux, N., E. Wajnberg, K.A.G. Wyckhuys, G. Burgio, S. Arpaia, C. A. Narvaez-Vasquez, J. Gonzalez-Cabrera, D. C. Ruescas, E. Tabone, J. Frandon, et al. 2010. Biological invasion of European tomato crops by Tuta absoluta: ecology, geographic expansion and prospects for biological control. J. Pest Sci. 83: 197-215.

Desneux, N., M. G. Luna, T. Guillemaud, and A. Urbaneja. 2011a. The invasive South American tomato pinworm, Tuta absoluta, continues to spread in Afro-Eurasia and beyond: the new threat to tomato world production. J. Pest Sci. 84: 403-408.

Desneux, N., J. Pizzol, C. Thomas, E. Pautrat, P. Bearez, C. Poncet, E. Tabone, F. Kabiri, and J. Frandon. 2011b. Potential for direct interference between natural enemies of Tuta absoluta on tomato. Acta Hortic. 917: 31-37. 
Desneux, N., R. Blahnik, C. J. Delebecque, and G. E. Heimpel. 2012. Host phylogeny and specialisation in parasitoids. Ecol. Lett. 15: 453-460.

Driessen, G., L. Hemerik, and B. Boonstra. 1991. Host selection behavior of the parasitoid Leptopilina clavipes, in relation to survival in hosts. Neth. J. Zool. 41: 99-111.

El-Wakeil, N. E. 2007. Evaluation of efficiency of Trichogramma evanescens reared on different factitious hosts to control Helicoverpa armigera. J. Pest Sci. 80: 29-34.

Farrar, R. R., J. D. Barbour, and G. G. Kennedy. 1994. Fieldevaluation of insect resistance in a wild tomato and its effects on insect parasitoids. Entomol. Exp. Appl. 71: 211226.

Fidgen, J. G., E. S. Eveleigh, and D. T. Quiring. 2000. Influence of host size on oviposition behaviour and fitness of Elachertus cacoeciae attacking a low-density population of spruce budworm Choristoneura fumiferana larvae. Ecol. Entomol. 25: 156-164.

Foerster, M. R., and L. A. Foerster. 2009. Effects of temperature on the immature development and emergence of five species of Trichogramma. Biocontrol 54: 445-450.

Gontijo, P. C., M. C. Picanço, E.J.E. Pereira, J. C. Martins, M. Chediak, and R.M.C. Guedes. 2013. Spatial and temporal variation in the control failure likelihood of the tomato leaf miner, Tuta absoluta. Ann. Appl. Biol. 162: 50-59.

Harvey, J. A., E. H. Poelman, and T. Tanaka. 2013. Intrinsic inter- and intraspecific competition in parasitoid wasps. Annu. Rev. Entomol. 58: 333-51.

Hawkins, B. A., H. V. Cornell, and M. E. Hochberg. 1997. Predators, parasitoids, and pathogens as mortality agents in phytophagous insect populations. Ecology 78: 21452152.

Hoffmann, M. P., P. R. Ode, D. L. Walker, J. Gardner, S. Van Nouhuys, and A. M. Shelton. 2001. Performance of Trichogramma ostriniae (Hymenoptera: Trichogrammatidae) reared on factitious hosts, including the target host, Ostrinia nubilalis (Lepidoptera: Crambidae). Biol. Control 21: 1-10.

Hoffmann, M. P., S. A. Pitcher, S. A. Cheever, J. Gardner, J. E. Losey, T. P. Kuhar, C. A. Laub, and R. R. Youngman. 2006. Efficacy of inoculative releases of Trichogramma ostriniae (Hymenoptera: Trichogrammatidae) against European corn borer Ostrinia nubilalis (Lepidoptera: Crambidae) in field corn. Biol. Control 36: 345-349.

Hopper, K. R., and R. T. Roush. 1993. Management of genetics of biological-control introductions. Genetics 38: 27-51.

Heimpel, G. E., C. Neuhauser, and M. Hoogendoorn. 2003. Effects of parasitoid fecundity and host resistance on indirect interactions among hosts sharing a parasitoid. Ecol. Lett. 6: 556-566.

Jaenike, J. 1978. Optimal oviposition behavior in phytophagous insects. Theor. Popul. Biol. 14: 350-356.

Janssen, A. 1989. Optimal host selection by Drosophila parasitoids in the field. Funct. Ecol. 3: 469-479.

Kauffman, W. C., and G. G. Kennedy. 1989. Relationship between trichome density in tomato and parasitism of Heliothis spp. (Lepidoptera, Noctuidae) eggs by Trichogramma spp. (Hymenoptera, Trichogrammatidae). Environ. Entomol. 18: 698-704.

Kazmer, D. J., and R. F. Luck. 1995. Field-tests of the sizefitness hypothesis in the egg parasitoid Trichogrammapretiosum. Ecology 76: 412-425.

Khanh, H.D.T., M. Tiradon, E. Colombel, A. Bonnet, A. Chailleux, N. Desneux, and E. Tabone. 2012. Using new egg parasitoids (Trichogramma spp.) to improve integrated management against Tuta absoluta. OEPP/EPPO Bull. 42: 249-254.
Keller, M. A. 1987. Influence of leaf surfaces on movements by the hymenopterous parasitoid Trichogramma-exiguum. Entomol. Exp. Appl. 43: 55-59.

Kolliker-Ott, U. M., F. Bigler, and A. A. Hoffmann. 2003. Does mass rearing of field collected Trichogramma brassicae wasps influence acceptance of European corn borer eggs? Entomol. Exp. Appl. 109: 197-203.

Lu, Y. H., K. M. Wu, Y. Y. Jiang, Y. Y. Guo, and N. Desneux. 2012. Widespread adoption of Bt cotton and insecticide decrease promotes biocontrol services. Nature 487: 362 365 .

Mackauer, M. 1996. Sexual size dimorphism in solitary parasitoid wasps: influence of host quality. Oikos 76: 265-272.

Mills, N. 2010. Egg parasitoids in biological control and integrated pest management, pp. 389-411. In F. L. Consoli, J.R.P. Parra, and R. A. Zucchi (eds.), Egg Parasitoids in Agroecosystems With Emphasis on Trichogramma. Springer, Dordrecht, The Netherlands.

Miranda, M.M.M., M. Picanco, J. C. Zanuncio, and R.N.C. Guedes. 1998. Ecological life table of Tuta absoluta (Meyrick) (Lepidoptera : Gelechiidae). Biocontrol Sci. Technol. 8: 597-606.

Nurindah, B. W. Cribb, and G. Gordh. 1999. Influence of rearing hosts on host size acceptance by Trichogramma australicum. Biocontrol 44:129-141.

Olson D. M., and D. A. Andow. 2006. Walking pattern of Trichogramma nubilale Ertle \& Davis (Hymenoptera; Trichogrammatidae) on various surfaces. Biol. Control 39.

Parra, J.R.P., and R. A. Zucchi. 2004. Trichogramma in Brazil: feasibility of use after twenty years of research. Neotrop. Entomol. 33: 271-281.

Pennacchio, F., and M. R. Strand. 2006. Evolution of developmental strategies in parasitic hymenoptera. Annu. Rev. Entomol. 51: 233-258.

Pintureau, B. 2009. La lutte biologique et les Trichogrammes: application au contrôle de la pyrale du maïs, $\mathrm{p}$. 262. Le Manuscrit, Paris, France.

Pizzol, J., B. Pintureau, O. Khoualdia, and N. Desneux. 2010. Temperature-dependent differences in biological traits between two strains of Trichogramma cacoeciae (Hymenoptera: Trichogrammatidae). J. Pest Sci. 83: 447-452.

Pizzol, J., N. Desneux, E. Wajnberg, and D. Thiery. 2012. Parasitoid and host egg ages have independent impact on various biological traits in a Trichogramma species. J. Pest Sci. 85: 489-496.

Pratissoli, D., and J.R.P. Parra. 2000. Fertility life table of Trichogramma pretiosum (Hym., Trichogrammatidae) in eggs of Tuta absoluta and Phthorimaea operculella (Lep., Gelechiidae) at different temperatures. J. Appl. Entomol. 124: 339-342.

Pratissoli, D., R. T. Thuler, G. S. Andrade, L.C.M. Zanotti, and A. F. da Silva. 2005. Estimate of Trichogramma pretiosum to control Tuta absoluta in stalked tomato. Pesquisa Agropecuária Brasileira 40: 715-718.

Roriz, V., L. Oliveira, and P. Garcia. 2006. Host suitability and preference studies of Trichogramma cordubensis (Hymenoptera: Trichogrammatidae). Biol. Control 36: 331-336.

Rutledge C. E., and R. J. O’Neil. 2005. Orius insidiosus (Say) as a predator of the soybean aphid, Aphis glycines Matsumura. Biol. Control 33:56-64.

Salt, G. 1937. The egg parasite of Sialis lutaria: a study of the influence of the host upon a dimorphic parasite. Parasitology 29: 539-53.

Salt, G. 1940. Experimental studies in insect parasitism. VII. The effect of different host on parasite Trichogramma 
evanescens Wests. (Hym.: Chalcidoidea). Proc. R. Entomol. Soc. Lond. A, General Entomol. 15: 81-95.

Smith, S. M. 1996. Biological control with Trichogramma: advances, successes, and potential of their use. Annu. Rev. Entomol. 41: 375-406.

Symondson, W.O.C., K. D. Sunderland, and M. H. Greenstone. 2002. Can generalist predators be effective biocontrol agents? Annu. Rev. Entomol. 47: 561-594.

Tabone, E., C. Bardon, N. Desneux, and E. Wajnberg. 2010. Parasitism of different Trichogramma species and strains on Plutella xylostella l. on greenhouse cauliflower. J. Pest Sci. 83: 251-256.

Tabone, E., C. Bardon, and N. Desneux. 2012. Study of dispersal as a selection criterion for Trichogrammatidae for biological control in cauliflower greenhouses. Acta Hortic. 927: 227-236.

Thomson, L. J., D. M. Bennett, D. C Glenn, and A. A. Hoffmann. 2003. Developing Trichogramma as a pest management tool, pp. 65-85. In O. Koul and G. S. Dhaliwal (eds.), Predators and Parasitoids. Taylor and Francis, London, United Kingdom.

van Alphen J.J.M., and L.E.M. Vet. 1986. An evolutionary approach to host finding and selection, pp. 23-61. In J. K. Waage and D. J Greathead (eds.), Insect Parasitoids. Academic, London, United Kingdom. van Driesche R. G., and T. S. Bellows. 1996. Biological control. Chapman \& Hall, New York, NY.

Yuan, X. H., L. W. Song, J. J. Zhang, L. S. Zang, L. Zhu, C. C. Ruan, and G. Z. Sun. 2012. Performance of four Chinese Trichogramma species as biocontrol agents of the rice striped stem borer, Chilo suppressalis, under various temperature and humidity regimes. J. Pest Sci. 85: 497-504.

Zappalà L., U. Bernardo, A. Biondi, A. Cocco, S. Deliperi, G. Delrio, M. Giorgini, P. Pedata, C. Rapisarda, G. Tropea Garzia, et al. 2012. Recruitment of native parasitoids by the exotic pest Tuta absoluta (Meyrick) in Southern Italy. Bull. Insectol. 65: 51-61.

Zappalà, L., A. Biondi, A. Alma, I. J. Al-Jboory, J. Arnò, A. Bayram, A. Chailleux, A. El-Arnaouty, D. Gerling, Y. Guenaoui, L. Shaltiel-Harpaz, G. Siscaro, M. Stavrinides, L. Tavella, R. Vercher Aznar, A. Urbaneja, N. Desneux. 2013. Natural enemies of the South American moth, Tuta absoluta, in Europe, North Africa and Middle-East, and their potential use in pest control strategies. J. Pest Sci. (in press) (doi:10.1007/s10340-013-0531-9).

Received 21 February 2013; accepted 10 September 2013. 